\title{
Contributions of Hippocampus and Striatum to Memory-Guided Behavior Depend on Past Experience
}

\author{
(D) Janina Ferbinteanu ${ }^{1,2}$ \\ Departments of ${ }^{1}$ Physiology and Pharmacology and ${ }^{2}$ Neurology, State University of New York Downstate Medical Center, Brooklyn, New York 11203
}

The hippocampal and striatal memory systems are thought to operate independently and in parallel in supporting cognitive memory and habits, respectively. Much of the evidence for this principle comes from double dissociation data, in which damage to brain structure A causes deficits in Task 1 but not Task 2, whereas damage to structure B produces the reverse pattern of effects. Typically, animals are explicitly trained in one task. Here, we investigated whether this principle continues to hold when animals concurrently learn two types of tasks. Rats were trained on a plus maze in either a spatial navigation or a cue-response task (sequential training), whereas a third set of rats acquired both (concurrent training). Subsequently, the rats underwent either sham surgery or neurotoxic lesions of the hippocampus (HPC), medial dorsal striatum (DSM), or lateral dorsal striatum (DSL), followed by retention testing. Finally, rats in the sequential training condition also acquired the novel "other" task. When rats learned one task, HPC and DSL selectively supported spatial navigation and cue response, respectively. However, when rats learned both tasks, HPC and DSL additionally supported the behavior incongruent with the processing style of the corresponding memory system. Thus, in certain conditions, the hippocampal and striatal memory systems can operate cooperatively and in synergism. DSM significantly contributed to performance regardless of task or training procedure. Experience with the cue-response task facilitated subsequent spatial learning, whereas experience with spatial navigation delayed both concurrent and subsequent response learning. These findings suggest that there are multiple operational principles that govern memory networks.

Key words: functional principles of memory circuits; hippocampus; learning; memory; memory systems; striatum

Significance Statement

Currently, we distinguish among several types of memories, each supported by a distinct neural circuit. The memory systems are thought to operate independently and in parallel. Here, we demonstrate that the hippocampus and the dorsal striatum memory systems operate independently and in parallel when rats learn one type of task at a time, but interact cooperatively and in synergism when rats concurrently learn two types of tasks. Furthermore, new learning is modulated by past experiences. These results can be explained by a model in which independent and parallel information processing that occurs in the separate memory-related neural circuits is supplemented by information transfer between the memory systems at the level of the cortex.

\section{Introduction}

Memory is not unitary; rather, there are different types of memories, with different properties and dynamics. The formulation of this organizational principle goes back to the debate between

Received March 14, 2016; revised May 3, 2016; accepted May 7, 2016.

Author contributions: J.F. designed research; J.F. performed research; J.F. analyzed data; J.F. wrote the paper.

This work has been supported by National Institutes of Health Grants MH106708 and MH094946 and by an internal State University of New York Downstate grant. I thank Yitzhok Becher, Judah Horowitz, Maiko lijima, Khiara Scolari, Metika Ngbokoli, and Isaac Buff for help with animal training and Fraser Sparks for help with lesion procedures. I also acknowledge Drs. Robert McDonald and Norman White for useful comments on previous versions of the manuscript and the two anonymous reviewers who provided valuable input.

The author does not have any conflicts of interest.

Correspondence should be addressed to Janina Ferbinteanu, Departments of Physiology and Pharmacology, and Neurology, State University of New York Downstate Medical Center, 450 Clarkson Avenue, Brooklyn, NY 11203. E-mails: janina.ferbinteanu@downstate.edu, ferbinteanu@gmail.com.

DOI:10.1523/JNEUROSCI.0840-16.2016

Copyright $\odot 2016$ the authors $\quad 0270-6474 / 16 / 366459-12 \$ 15.00 / 0$
Hull and Thorndike, who thought that stimulus-response (S-R) associations were sufficient to generate adaptive behavior (Hull, 1930; Thorndike, 1932), and Tolman, who argued that animals additionally form flexible cognitive representations by learning stimulus-stimulus (S-S) associations (Tolman, 1948). Eventually, Tolman's view prevailed, and it became apparent that these memories also involve separate neurobiological substrates when surgical resection of medial temporal lobes in patient H.M. resulted in profound amnesia (Scoville and Milner, 1957; Penfield and Milner, 1958), a loss of the ability to learn and remember factual information or autobiographical events (declarative memory). Despite the severity of their deficit in the declarative domain, amnesics can form memories for motor skills (Corkin, 1968; Milner et al., 1968), which are dependent on the neostriatum (Heindel et al., 1988), a part of the basal ganglia more generally involved in habits (Knowlton et al., 1996). These and other 
findings generated the memory systems theory, which posits that different types of memories are supported by distinct neural circuits with individual characteristics of information processing that operate independently and in parallel (Squire, 2004).

Declarative memories, so named because in humans they can be consciously expressed (declared) verbally, are flexible, form fast, and involve storage of S-S associations. In contrast, habits do not require consciousness, are rigid, form gradually, and are based on remembering S-R associations (White and McDonald, 2002). The term "declarative" implies verbal language, but in animals, spatial learning is representative for declarative memory because it involves a flexible spatial cognitive map (O'Keefe and Nadel, 1978). In contrast, habits can be modeled by memories for cue-response associations or body turns. Studying memory types by changing the contingencies of the task within the same experimental setting has been successfully used to demonstrate the operational principle of independent parallelism by revealing double dissociations, in which damage to brain structure A causes deficits in Task 1 but not Task 2, whereas damage to structure B produces the reverse pattern of effects. For example, directly drawing on Tolman's original work (Tolman et al., 1946), Packard and McGaugh (1996) trained rats to walk from the south start arm of a plus maze to find food in the west arm. When placed on the previously blocked north arm early in the training, most rats continued to go to the west arm, demonstrating place learning, which was abolished by HPC, but not dorsal striatum (DS), inactivation. In contrast, later in training, most rats now chose the east arm, maintaining the body turn and demonstrating response learning. HPC inactivation had no effect, but DS inactivation resulted in a return to the spatial strategy.

Using a similar approach, recording experiments targeting the activity of CA1 hippocampal neurons under known memory demand employed a behavioral paradigm consisting of two tasks: (1) spatial navigation and (2) cue response (Ferbinteanu et al., 2011). The extensive literature on memory systems predicts that in this paradigm, HPC should selectively support spatial navigation, but empirical data showed that damage in the medial temporal lobe impaired cue response (O'Reilly et al., 2014). To systematically investigate the influence of past experience on the contributions of HPC and DS memory systems to behavior, we trained rats either sequentially in one of the two tasks or concurrently in both tasks (Fig. $1 A$ ). After reaching a set criterion, the animals received sham surgery or selective lesions of the HPC, DSM, or DSL (cue-response associations depend mostly on DSL, whereas DSM supports behavioral flexibility: Devan et al., 1999, 2011; Yin and Knowlton, 2004; Ragozzino et al., 2009; Baker and Ragozzino, 2014). After recovery, all animals were tested for re- tention across 5 consecutive days, and then animals in the sequential condition were trained in the "other" task (Fig. 1B).

\section{Materials and Methods}

Subjects

Male Long-Evans rats (300-350 g, 4-6 months old; Charles River and Harlan) were housed in individual cages ( $12 \mathrm{~h}$ light cycle; animals were tested during the day cycle). After acclimation, the animals were food deprived to $85-90 \%$ of ad libitum body weight and maintained at this level for the rest of the procedures (allowing adjustment for normal growth). All procedures met National Institutes of Health guidelines and were approved by the Institutional Animal Care and Use Committee. A total of 162 animals participated in this study, but memory retention was evaluated in 18 sham controls and 54 rats with selective and inclusive brain lesions of the targeted areas (six subjects per lesion group per condition). Acquisition of the behavioral paradigm, which occurred before the surgery, was evaluated based on the performance of the entire group of 162 rats.

\section{Apparatus}

The plus maze was made of gray polyvinyl chloride (PVC) and elevated $91 \mathrm{~cm}$ from the floor of a room that contained several visual cues. Each of the four arms was $61 \mathrm{~cm}$ long and $6.3 \mathrm{~cm}$ wide. A gray PVC block (30.4 $\mathrm{cm}$ high, $6.3 \mathrm{~cm}$ wide, $15.2 \mathrm{~cm}$ deep) was used to block the start arm that was not in use for that trial. A rectangular waiting platform $(32 \times 42 \mathrm{~cm})$ 
was placed next to the maze. In the cued version of the task, a white visible flag also made of PVC was used to indicate the location of the food on the maze; during the spatial version of the task, the cue was placed on a table in the room and off the maze.

\section{Behavioral training and testing}

All animals were preexposed to the maze in the presence of food for 2 consecutive days and then trained to walk from either the north or the south start arms to the end of west or east goal arms to obtain half a Fruit Loop. Between trials, the rats were placed on a side platform to wait for the next trial. Entry with all four paws into the unrewarded arm defined an error, which the rat was allowed to correct. Training procedures followed previously published protocols (Ferbinteanu and Shapiro, 2003; Ferbinteanu et al., 2011) and used a spatial navigation task with serial reversals and a cue-response task (Fig. 1). In both cases, the start and the goal arm were selected based on a pseudorandom sequence of 60 trials with no more than three consecutive repetitions of the same type of journey (northeast, northwest, southeast, or southwest).

Spatial task. In the spatial task, the animals were rewarded for remembering spatial location. The position of the food was kept constant until the rat entered the correct goal arm in 9 of 10 consecutive trials. At that point, the other goal arm was baited and a new block of trials began. If the animal did not reach the criterion in a maximum of 20 trials at the beginning of training or 15 trials once it was familiar with the task, the location of the food was changed automatically to avoid unbalanced reinforcement of any specific goal arm. Alternating trial blocks continued up to either four blocks or 60 total trials.

Cue task. In this case, the rats had to remember an association between the visible cue, whose location was rendered irrelevant by changing start and goal positions based on a pseudorandom sequence, and a motor response, which was the walk toward the cue. Animals received 45 trials in each session, approximately the same number of trials necessary to complete four blocks of trials in the spatial task. Thus, each goal arm was rewarded approximately equally both within and across tasks.

Experiment 1: retention in spatial navigation task; acquisition of cue response. One set of animals was first trained in spatial navigation only. Training continued until the rats reached a criterion of $80 \%$ correct choices for 2 consecutive days, after which they were assigned to one of four groups: (1) HPC lesions; (2) DSM lesions; (3) DSL lesions; and (4) sham controls. After a recovery interval of $5-10 \mathrm{~d}$, retention of the spatial task was evaluated for 5 consecutive days and then all animals were trained in the cue-response task.

Experiment 2: retention in cue-response task; acquisition of spatial navigation. Procedures were similar as in Experiment 1, except that animals were first trained and tested in the cue-response task and then acquired spatial navigation.

Experiment 3: concomitant training in spatial navigation and cue-response tasks. All rats started training in the cue task. When the animals readily responded to the cue $(2-3 \mathrm{~d})$, they were introduced to the spatial navigation task and continued with daily training in both tasks. The order in which the two tasks were presented within a session was varied to avoid an order effect. When the rats reached $80 \%$ correct performance in both tasks for 2 consecutive days, they were assigned to one of four groups: (1) HPC lesions; (2) DSM lesions; (3) DSL lesions; and (4) sham controls. After recovery, retention was evaluated for 5 consecutive days in both tasks.

\section{Lesions}

Rats were anesthetized with isoflurane and diazepam or midazolam (10 $\mathrm{mg} / \mathrm{kg}$ ). Atropine ( $5 \mathrm{mg} / \mathrm{kg}$ body weight) was also administered to avoid fluid accumulation in the respiratory tract. Neurotoxic lesions were made by injecting either a solution of $5 \mathrm{mg} / \mathrm{ml} \mathrm{NMDA}$ in phosphate buffer, $\mathrm{pH} 7.4$, or a quinolinic acid $(30 \mathrm{mg} / \mathrm{ml}$ in phosphate buffer titrated with sodium hydroxide to $\mathrm{pH} 7.4$ ) through a 30-gauge cannula attached to a minipump $(0.2 \mu \mathrm{l} / \mathrm{min}$; model NE-4000; New Era Pump Systems). At the end of each injection, the cannula was left in place for 3 min, retracted $0.5 \mathrm{~mm}$ and left in this location for $1 \mathrm{~min}$, and then slowly retracted completely. The coordinates of each injection and the volumes injected are presented in Table 1. To prevent seizure development, a

\section{Table 1. Lesion coordinates}

$$
\begin{aligned}
& \text { HPC lesions } \\
& \text { 1) }-3.1, \pm 1.0,-3.6,0.25 \mu \mathrm{l} \\
& \text { 2) }-3.1, \pm 2.0,-3.6,0.25 \mu \mathrm{l} \\
& \text { 3) }-4.1, \pm 2.0,-4.0,0.25 \mu \mathrm{l} \\
& \text { 4) }-4.1, \pm 3.5,-4.0,0.25 \mu \mathrm{l} \\
& \text { 5) }-5.0, \pm 3.0,-4.1,0.3 \mu \mathrm{l} \\
& 6)-5.0, \pm 5.2,-5.0,0.3 \mu \mathrm{l} \\
& \text { 7) }-5.0, \pm 5.2,-7.3,0.3 \mu \mathrm{l} \\
& 8)-5.8, \pm 4.4,-4.4,0.3 \mu \mathrm{l} \\
& \text { 9) }-5.8, \pm 5.1,-6.2,0.40 \mu \mathrm{l} \\
& \text { 10) }-5.8, \pm 5.1,-7.5,0.40 \mu \mathrm{l}
\end{aligned}
$$

DSM lesions

$$
\begin{aligned}
& \text { 1) }+1.6, \pm 1.9,-4.8,0.20 \mu \mathrm{l} \\
& \text { 2) }+0.5, \pm 2.2,-5.0,0.20 \mu \mathrm{l} \\
& \text { 3) }-0.8, \pm 2.8,-3.6,0.20 \mu \mathrm{l}
\end{aligned}
$$

DSL lesions

$$
\begin{aligned}
& \text { 1) }+1.6, \pm 3.0,-6.2,0.23 \mu \mathrm{l} \\
& \text { 2) }+0.8, \pm 3.7,-6.6,0.23 \mu \mathrm{l} \\
& \text { 3) }-0.5, \pm 4.5,-6.6,0.23 \mu \mathrm{l}
\end{aligned}
$$

Coordinates are shown as anteroposterior, lateral, and ventral from bregma (in $\mathrm{mm}$ ).

second intraperitoneal injection of valium ( $10 \mathrm{mg} / \mathrm{kg}$ body weight) was administered before neurotoxin infusion, and animals were monitored until completely awake and active in their home cages. Sham animals were anesthetized, incised, and sutured.

\section{Behavioral data analysis}

Percentage performance error was calculated for each rat during each day of testing, and a mean was calculated for each group during each day. Differences in performance were assessed using two-way ANOVAs (SAS Institute). Time (in days) and lesion groups as categorical independent variables and performance as percentage error on repeated time points as a dependent variable were entered into the model. When overall analyses indicated significant differences, we focused on simple effects; when simple effects were significant, we proceeded to perform post hoc multiple comparisons adjusted by the Student-Newman-Keuls procedure. We also investigated learning during the training phase (before surgery) by computing the frequency distributions for the number of training days to criterion in each of the three training conditions. We compared these distributions using a Kolmogorov-Smirnov test (SAS Institute).

\section{Tissue preparation and processing for histology}

Rats were overdosed with isoflurane (administered in closed environment) and perfused transcardially with normal saline and then $10 \%$ Formalin for tissue fixation. Coronal sections $(40 \mu \mathrm{m})$ were cut on a cryostat and stained with cresyl violet to evaluate the extent of the lesion.

\section{Lesion assessment}

Brains were sectioned coronally. Each fourth section in the striatum lesion groups, and each fifth section in the hippocampal lesion groups was mounted on a microscope slide to be used for lesion evaluation. We first inspected visually under the microscope and traced each lesion on a set of histological plates (Paxinos and Watson, 1988). Data from animals whose lesions were insufficiently inclusive (i.e., encompass most of the targeted area) and selective (i.e., extended bilaterally to significant portions of other brain areas) were excluded from additional analysis. The lesions that passed criterion underwent quantification analysis. We used for this purpose every second preserved section from rats with hippocampal lesions and every third preserved section from rats with striatal lesions. For each of these brain sections, we overlaid a $17 \times 34$ grid on a $20 \times$ magnification image of the area of interest $(600 \times 800$ pixels $)$ and counted the grid units that covered healthy tissue. This procedure was also performed for brain tissue from two control animals for the DS and two control animals for the HPC. The number of grid units from the control animals were summed up to obtain the total DS or HPC areas, respectively, and then the two values were averaged to obtain an estimate of healthy HPC and DS "volumes," respectively (because the brain tissue was sampled at regular intervals of $200 \mu \mathrm{m}$ for all HPC tissue and $160 \mu \mathrm{m}$ 


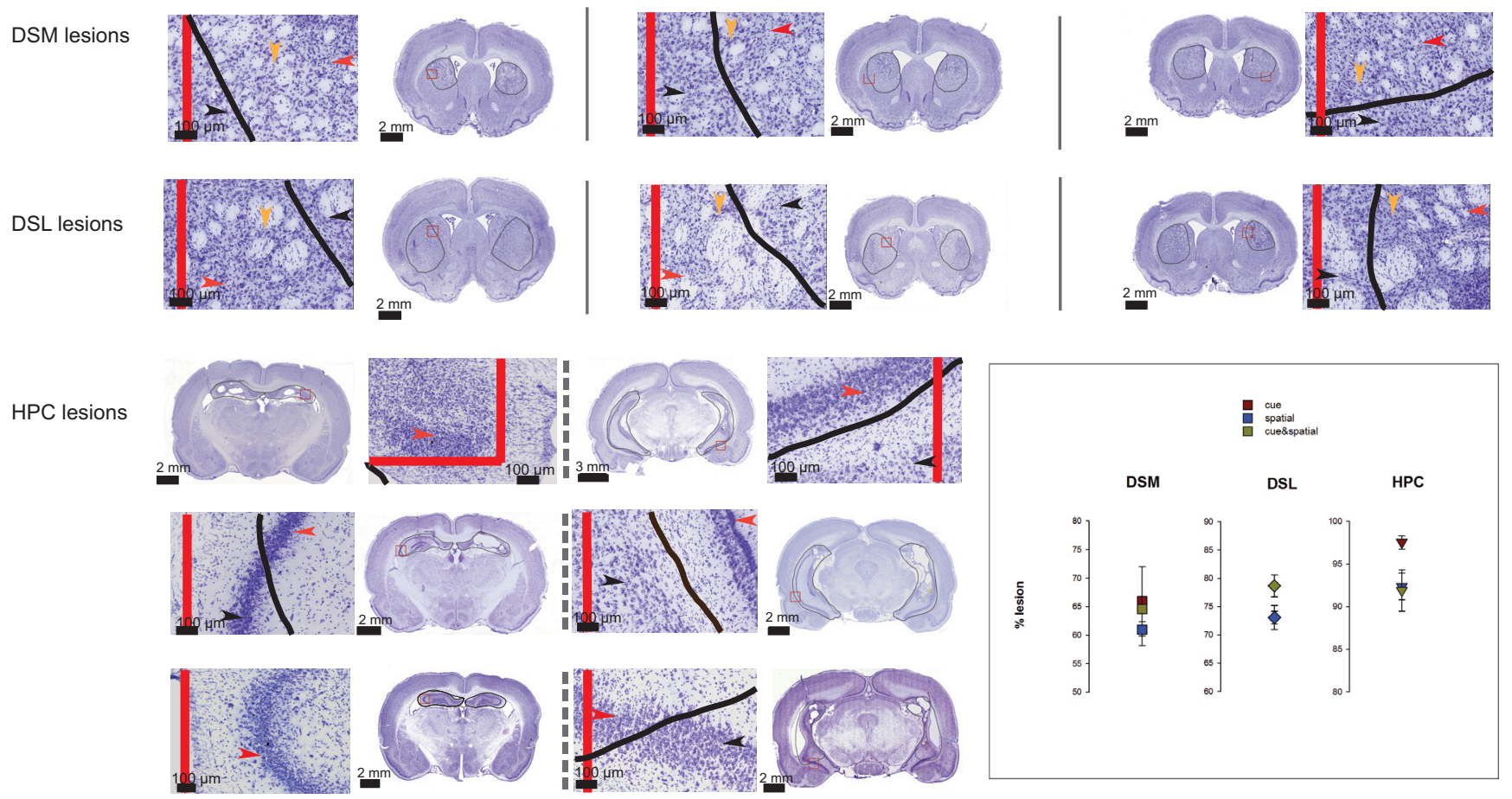

Figure 2. Lesions were localized in the targeted areas. Each of the nine lesion groups is represented by one lesion illustration. Photomicrographs of coronal sections through the brain shown at low magnification indicate the lesion area (circled in black) for examples of DSM lesions (top row), DSL lesions (second row), and HPC lesions (bottom rows; left, dorsal pole; right, ventral pole). Magnified sections of the areas marked by the red squares are displayed next to the corresponding section. Red and black lines represent the edge of the red square and the border of the lesion, respectively, as they appear at the higher magnification. For DSM and DSL lesions, the quantification encompassed all tissue showing gliosis regardless of whether principal neurons were completely eliminated (red arrowheads) or still present among the astrocytes (orange arrowheads). Tissue considered healthy (black arrowheads) did not present astrocytic invasion. Similarly, for HPC lesions, the quantification encompassed areas completely devoid of neurons (dorsal HPC, red arrowhead) and areas of neural degeneration (ventral HPC; red arrowhead; compare degenerating HPC neurons with the healthy neurons in the adjacent cortex indicated by black arrowhead). The results of the quantification analysis indicated that lesion size did not differ across training conditions for any experimental group ( $n=6$ rats per group; inset to the right).

for all DS tissue in control and lesion animals alike, multiplying by the constant distance between sections was not necessary to obtain an estimate of the lesion as percentage from the total structure). Percentage of healthy tissue was computed by dividing the number of grid units covering healthy tissue in a lesioned brain by the number of grid units corresponding to the area in a control brain; the percentage lesion was obtained then as the difference from percentage healthy tissue to $100 \%$. For each lesion group, we compared the percentage damage across the three experimental conditions using one-way ANOVA (SAS Institute).

\section{Results}

\section{Lesions encompassed the intended brain areas}

We evaluated for each animal the inclusivity and selectivity of the lesion, and we incorporated for analysis only data from animals with damage restricted to the intended brain areas. Cortical damage was small, if present, which was typically not the case. In the DS, the medial and lateral areas are not clearly delimited. Here we aimed for lesions as inclusive as possible that would conform to known topography of anatomical connections (McGeorge and Faull, 1989). We considered as lesioned all striatal tissue with signs of gliosis, regardless of whether the principal neurons might have been spared at the periphery of the affected area (Fig. 2, top two rows). As a group, the lesions distinguished well between the medial and lateral areas of the DS. Lesions of the HPC encompassed all its fields (dentate gyrus, CA3, CA1) in both the dorsal and ventral areas, and most of the lesions were nearly complete. The entorhinal cortex and other nearby cortical areas were not affected (Fig. 2, bottom rows). There was minor damage to the subiculum in the anterior areas. Quantification of the lesion sizes indicated that, within each lesion group, the extent of the lesions was similar across the three training conditions (DSM, $F_{(2,15)}=$ $0.4, p=0.6777$; DSL, $F_{(2,15)}=3.26, p=0.0666$; HPC, $F_{(2,15)}=$ $3.32, p=0.0639$; Figs. $2 A$, right inset, 3 ).

When animals learned one task, HPC and DSL lesions selectively affected place and response memory, respectively The memory systems theory postulates that the hippocampal and striatal memory systems have distinct preferred modes of information processing that result in distinct forms of representation: S-S and S-R, respectively. In turn, these representations guide different types of memory-based behaviors, such as spatial navigation and habits, entailing that HPC lesions would impair performance in the spatial navigation but not cue-response task, and conversely, that DSL lesions would impair performance in the cue-response but not spatial navigation task. If DSM is involved in behavioral flexibility (Ragozzino, 2007), then DSM function should be involved in both tasks to support the change in overt motor response necessary to reach the goal, as suggested by previous results (Devan and White, 1999; Ragozzino et al., 2009; Baker and Ragozzino, 2014). The empirical results obtained in the current experiment validated these predictions (Fig. $4 A$ ).

Overall, the lesions caused marked deficits in both cases (spatial task, $F_{(3,20)}=28.92, p<0.0001$; cue-response task, $\left.F_{(3,20)}=12.51, p<0.0001\right)$, and training across days improved performance (spatial task, $F_{(4,80)}=4.89, p=0.0014$; cue-response task, $\left.F_{(4,80)}=9.04, p<0.0001\right)$. In the spatial navigation task, not surprisingly, HPC lesions severely and permanently impaired performance. In contrast, animals with DSL lesions were not significantly different from controls on this task, and their 
DSM- cue\&spatial

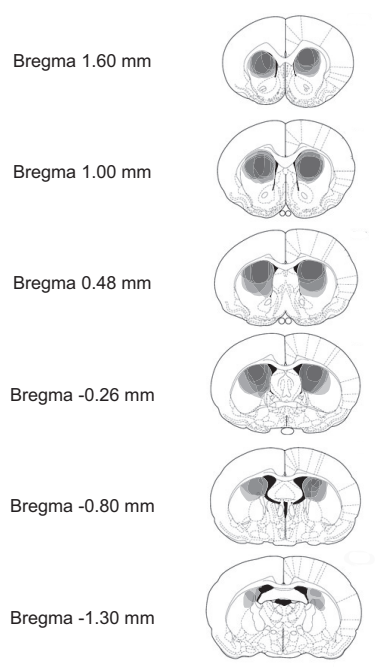

DSL- cue\&spatial

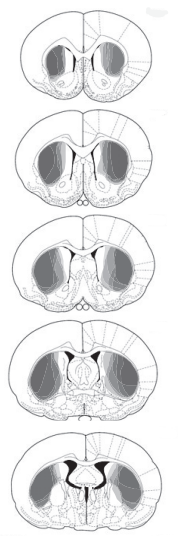

Bregma $-0.80 \mathrm{~mm}$

Bregma $-1.30 \mathrm{~mm}$

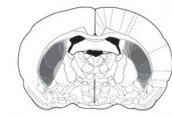

HPC- cue\&spatial

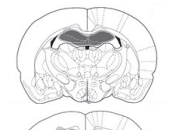

Bregma - $-3.14 \mathrm{~mm}$

Bregma $-4.40 \mathrm{~mm}$

Bregma $-5.20 \mathrm{~mm}$

Bregma $-5.60 \mathrm{~mm}$

Bregma $-6.04 \mathrm{~mm}$
DSM-cue

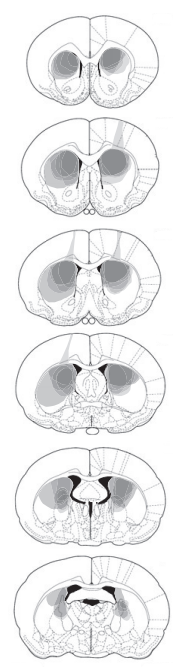

DSL-cue
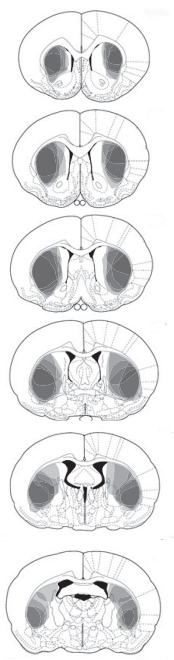

HPC-cue

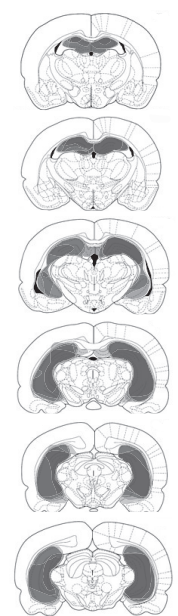

DSM-spatial

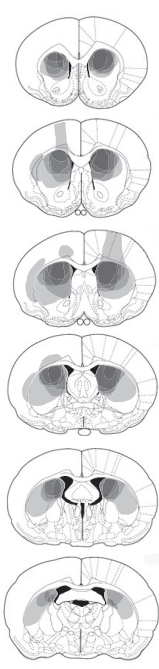

DSL-spatial
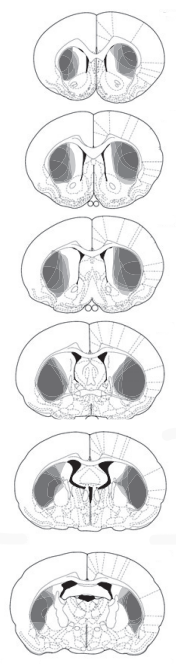

HPC-spatial

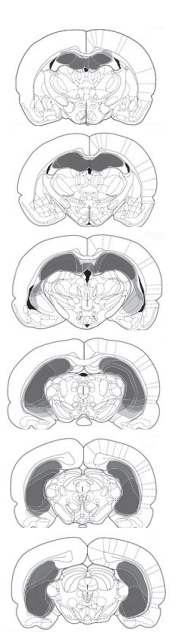

Figure 3. Total extent of lesions. For each animal whose lesions were deemed inclusive and selective, lesioned areas were marked on a single set of diagrams extracted from the Paxinos and Watson atlas (Paxinos and Watson, 1998). The corresponding diagrams were then superimposed for each lesion group separately for each training condition. Thus, within each group, areas performance benefited somewhat from training $\left(F_{(4,20)}=5.29, p=0.0045\right)$. As expected, DSM lesions also impaired spatial navigation, initially at a level similar to the one produced by HPC lesions. The data suggested that training helped some animals to reduce the handicap, but as a group, rats with DSM lesions did not improve significantly across days, and never attained control levels of performance. In the cue-response task, DSL lesions produced a significant and persistent deficit. The DSM group showed relearning with extended training $\left(F_{(4,20)}=4.68, p=\right.$ 0.0079 ) but not sufficient to reach control level. In contrast, the HPC group was not different from controls except during day 2 of retention testing, when it made slightly more errors even while still performing at criterion level (mean \pm SE: HPC, $18.67 \pm 1.62 \%$ error vs sham, $9.83 \pm 1.80 \%$ error); the performance of this group improved significantly during retention testing $\left(F_{(4,20)}=3.46, p=\right.$ $0.0195)$. It is interesting that, when compared with previous results of rats with HPC lesions trained in the cue-response task (Ferbinteanu et al., 2011), the animals in the current experiment seemed to have made more errors. The difference between the two studies is that here, the HPC lesions were larger, almost complete in fact (percentage lesion mean $\pm \mathrm{SE}$, $92.35 \pm 1.55$ ). This group showed a flat learning curve when they were subsequently trained in the spatial task. Their counterparts in the spatial navigation task, who had similar levels of HPC damage (percentage lesion mean $\pm \mathrm{SE}$, $97.54 \pm 0.77$ ), also failed to improve across the $5 \mathrm{~d}$ of retention testing but learned faster the cue-response task (see below), confirming previous studies indicating improvement on acquisition of S-R types of tasks in animals with HPC lesions (Packard et al., 1989; McDonald and White, 1993; Chang and Gold, 2003). Thus, in this study, the HPC lesions that produced a very profound and permanent deficit in spatial navigation did not cause a significant deficit in an already learned cue-response type of behavior, while speeding its rate of acquisition. Overall, these results reproduce previous findings that led to the formulation of the principle of independent parallelism proposed by the memory systems theory, while at the

lesioned in all six animals are represented as darkest gray, whereas areas lesioned in only one animal are represented in lightest gray. 
A

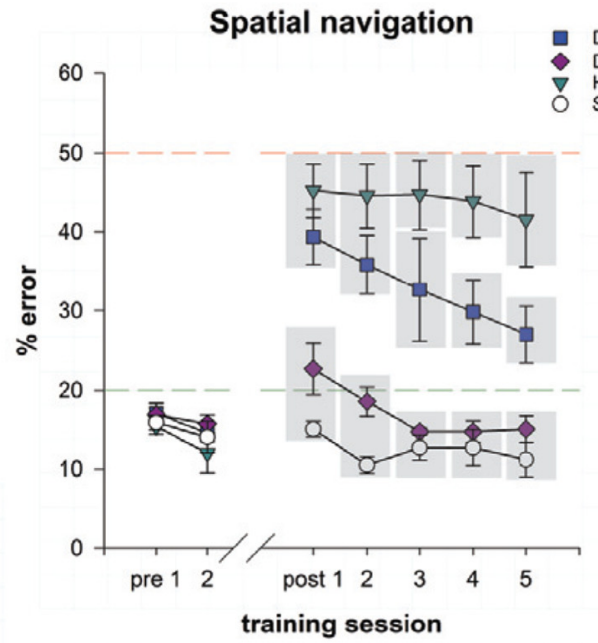

B

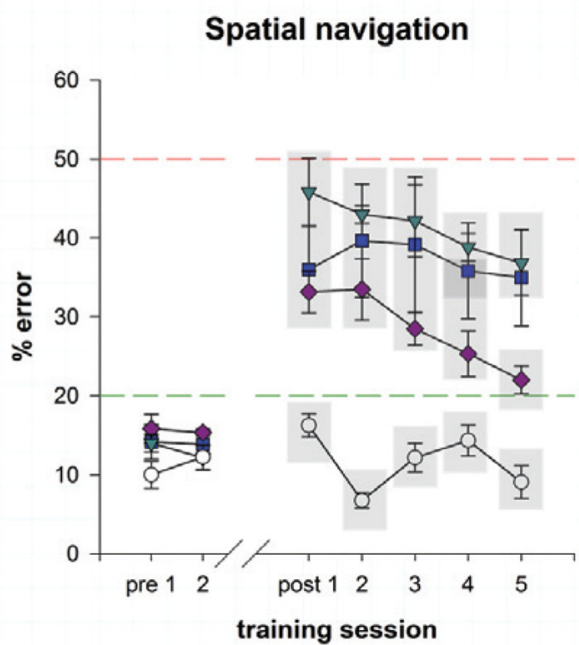

C
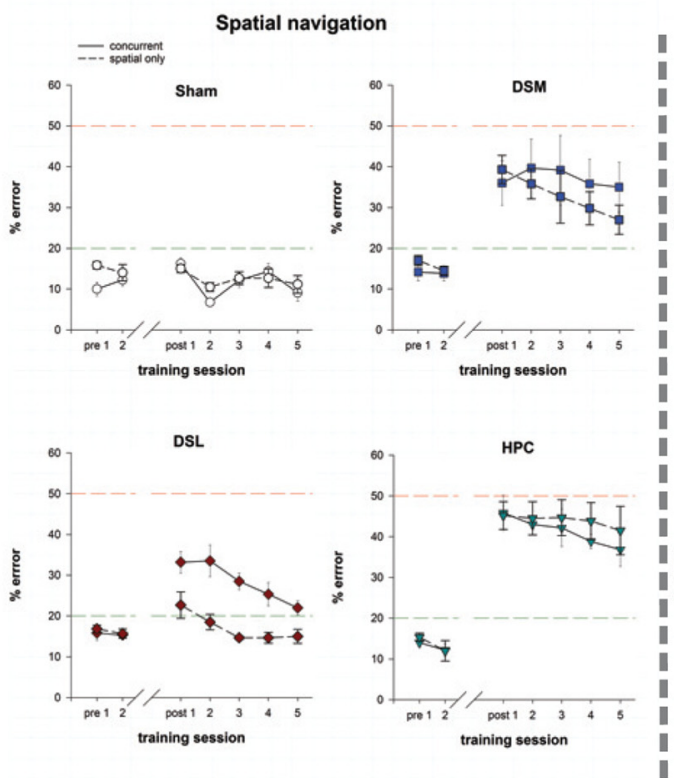

Cue response

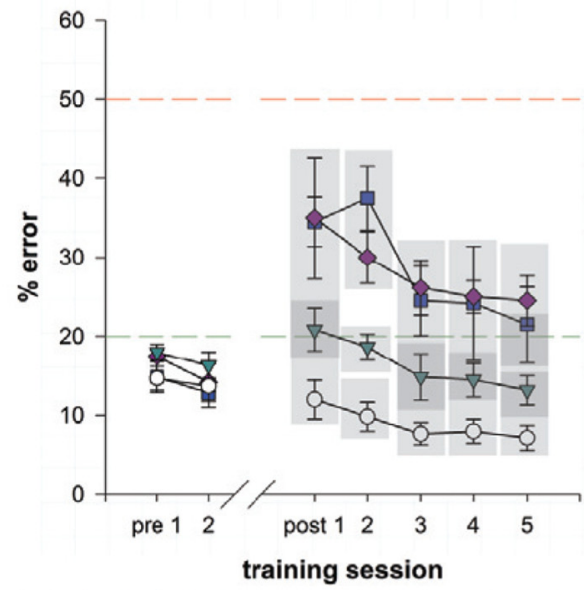

Cue response

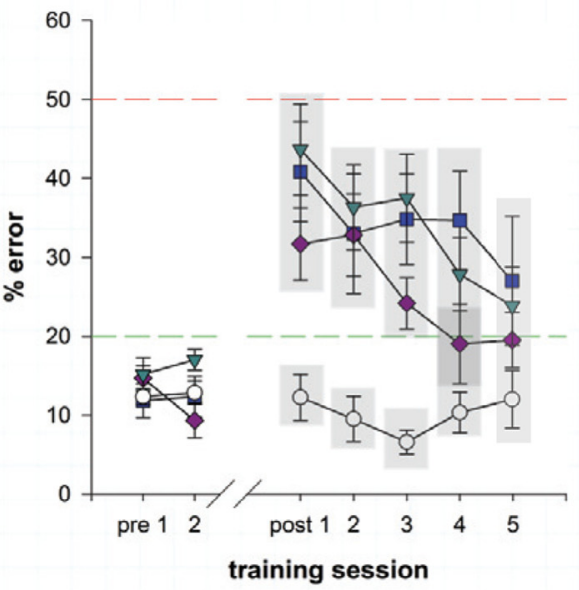

Figure 4. Retention in the two training conditions. $A$, When animals were trained in one of the two tasks ( $n=6$ rats per group), HPC selectively impaired spatial memory, whereas DSL lesions selectively impaired cue response. DSM lesions had an effect in both cases. $\boldsymbol{B}$, When animals were trained concurrently in both tasks ( $n=6$ rats per group), HPC lesions additionally impaired cue-response performance, and conversely, DSL lesions additionally affected spatial navigation. DSM continued to affect memory for both types of memories. (Figure legend continues.) 
same time validating the finding that hippocampal and striatal memory systems can interact competitively. The data also were in agreement with the idea that DSM is necessary for maintaining the plasticity of overt motor behavior so that it can be instrumental in reaching goals, although we found evidence of stereotyped behavior (i.e., persevering in a particular body turn regardless of circumstances) in only three of the total of 12 animals with DSM lesions.

\section{Concurrent training in the two tasks markedly modified the contributions of HPC and DSL to behavioral performance}

If the principle of independent parallelism is universally valid, then the double dissociation pattern of results obtained when animals learn only one task at a time should continue to be present when the animals learn the tasks concurrently. However, contradicting this view, in rats concurrently trained in the two tasks described above, the principle of independent parallelism was no longer valid (Fig. 4B).

Overall, lesions had a strong effect in both tasks (spatial task, $F_{(3,20)}=13.26, p<0.0001$; cue-response task, $F_{(3,20)}=7.09, p=$ 0.002 ) that diminished with training across days (spatial task, $F_{(4,80)}=5.52, p=0.0006$; cue-response task, $F_{(4,80)}=8.27, p<$ $0.0001)$. HPC lesions severely and permanently impaired spatial navigation with no evidence of learning across the $5 \mathrm{~d}$ of retention testing, whereas DSL lesions interfered with performance in the cue-response task. DSM lesions had as strong of an effect as HPC lesions on spatial navigation, which they permanently impaired, and had an overall marked but somewhat less severe effect on cue response $\left(F_{(4,20)}=3.71, p=0.0205\right)$, although three of the six animals in this group showed strong stereotyped behavior. Thus, in these aspects, HPC, DSL, and DSM continued to support behavioral performance in a pattern corroborating previous findings. However, the consistencies stopped here. DSL lesions also caused a severe spatial deficit, initially producing as much impairment as HPC and DSM lesions. The deficit diminished progressively $\left(F_{(4,20)}=4.55, p=0.0018\right)$, but performance never reached control level. Similarly, HPC lesions impaired the cueresponse behavior as strongly as DSM and DSL lesions. The magnitude of the effect also diminished gradually $\left(F_{(4,20)}=\right.$ $3.05, p=0.0407)$, but in the last day of retention testing, the HPC group was on average still above the $20 \%$ error criterion threshold.

We then directly compared the performance of the four experimental groups across training conditions for each of the two tasks (Fig. 4C). In normal animals and animals with DSM lesions, the training method had no effect regardless of the type of behavioral strategy. Overall, the performance varied across days for shams (spatial task, $F_{(4,40)}=7.80, p<0.0001$; cue-response task, $\left.F_{(4,40)}=3.01, p=0.03\right)$, although the data did not suggest any additional improvement. The DSM group did not show improvement across days in the spatial task either, but did so in the cue task $\left(F_{(4,40)}=6.47, p=0.0004\right)$. Second, training method did not affect the spatial navigation performance of animals with HPC lesions, nor the cue response performance of animals with

\section{$\leftarrow$}

(Figure legend continued.) C, Same data as above reorganized to facilitate comparing retention performance after sequential versus concurrent training. In all graphs, vertical axis shows percentage error in behavioral performance (mean \pm SEM). The red horizontal line at $50 \%$ level indicates chance performance, when a rat would choose randomly between the two arms. The green horizontal line indicates the criterion threshold of $20 \%$. Gray rectangles refer to the results of post hoc Student-Newman-Keuls multiple comparisons test; data points included in the same rectangle are not significantly different.
DSL lesions. In contrast, the training method heavily affected the performance of rats with HPC lesions in the cue-response task $\left(F_{(1,10)}=21.08, p=0.001\right)$ and the performance of rats with DSL lesions in the spatial task $\left(F_{(1,10)}=25.187, p=0.0005\right)$. The magnitude of the effect diminished across days for HPC lesions in the cue-response task $\left(F_{(4,40)}=5.0, p=0.0023\right)$ but not the spatial task, whereas DSL lesions allowed relearning in both tasks (spatial navigation, $F_{(4,40)}=8.27, p<0.0001$; cue response, $\left.F_{(4,40)}=5.07, p=0.0021\right)$. Together, all these results suggest that when animals learned only one task, the HPC and DS memory systems were selectively involved in guiding behavior based on S-S and S-R types of representations, respectively. In contrast, when training involved concurrent acquisition of tasks, the contributions of HPC and DS memory systems to behavior changed radically and no longer selectively supported only one type of behavioral strategy.

\section{Learning one type of task distinctly modulated subsequent acquisition of the other task}

The results above suggest that the neurobiological basis of memory-guided behavior is not set but depends on past experience. If so, does past experience also influence new learning? To address this issue, we submitted each of the groups in the sequential training condition to training in the task that would have been novel to them at that point. The results suggest that, indeed, the activity of one memory system may have long-term effects on the ability of a different memory system to guide behavior (Fig. 5).

The four groups differed significantly in both spatial $\left(F_{(3,20)}=\right.$ 8.73, $p=0.0007)$ and cue-response $\left(F_{(3,20)}=3.58, p=0.032\right)$ learning. Normal animals proficient at the cue-response task immediately switched strategy and performed close to the $20 \%$ criterion threshold during day 1 of exposure to spatial navigation, after which their accuracy further improved $\left(F_{(4,20)}=6.73, p=\right.$ $0.0013)$. A similar process seemed to occur in animals with DSM lesions, who performed close to control levels throughout. In contrast, the DSL lesion group, which was similar to the DSM group on retention of cue-response associations, could not transfer immediately the previous experience when acquiring spatial navigation but rather gradually improved across days of repeated exposure to the task $\left(F_{(4,20)}=4.3, p=0.0113\right)$ to eventually reach control level. The HPC lesion group, which performed at normal levels during the cue-response task, was severely impaired on spatial navigation and never recovered the memory deficit. Thus, normal animals could quickly switch from an S-R to an S-S strategy based on a process independent of DSM function. Storing a cue-response association was not sufficient to help animals with HPC lesions on the spatial navigation task, on which they consistently performed poorly.

The facilitation of spatial learning after cue-response training seen in the sham group may be a nonspecific effect generated by familiarity with the environment and/or the basic rule of the new task (i.e., walk on the maze to collect food). If that were the case, then normal animals trained in spatial navigation should have been able to use their experience to perform well when exposed to the cue-response task. However, this was not the case. Rather, the normal group well versed in spatial navigation did not perform at $20 \%$ criterion level on any of the $5 \mathrm{~d}$ of cue-response acquisition. Among the lesion groups, none showed a statistically significant facilitating effect of past experience during the first day of cue-response training, although the HPC lesion group significantly improved their performance from day 1 to day 2 of testing $\left(t_{(11)}=2.99, p=0.05\right)$, and, during day 3 , these animals 
A

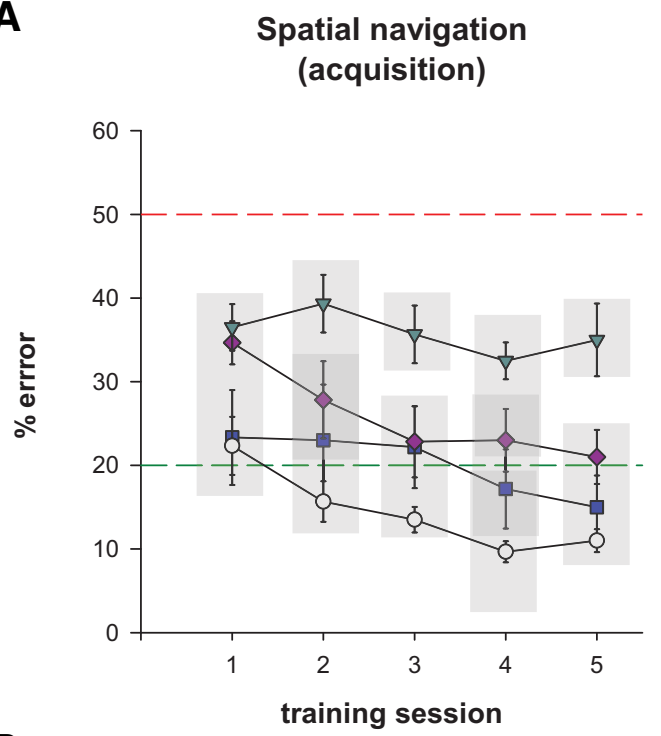

Cue response

(acquisition)

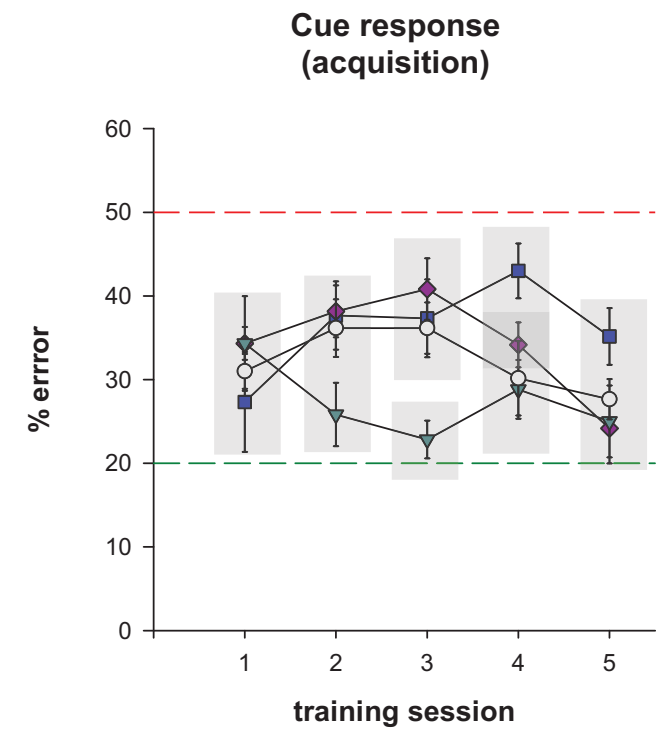

sham

DSM

DSL

HPC

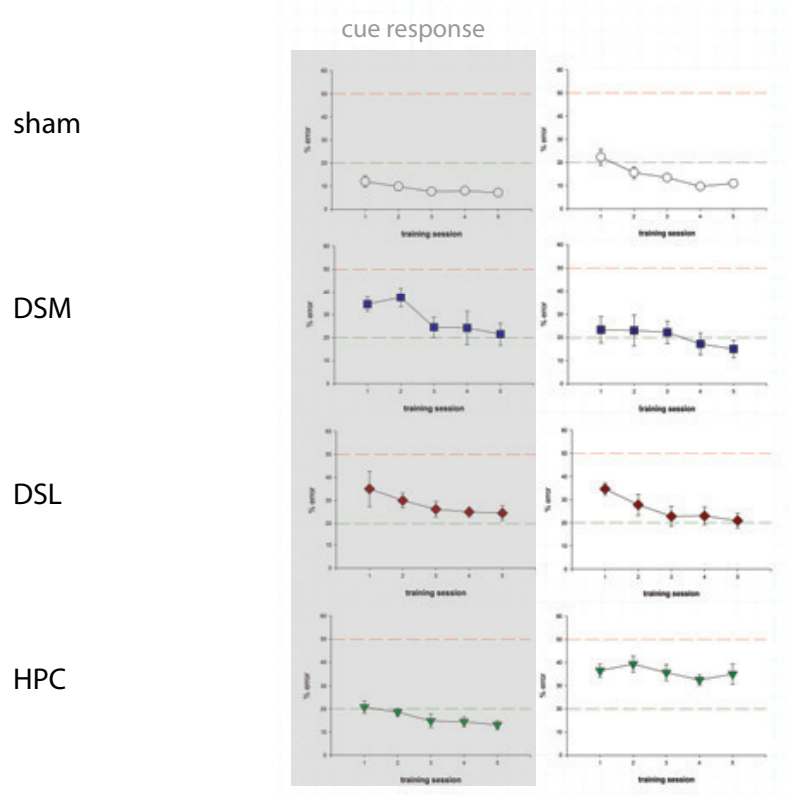

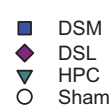

Sham

B

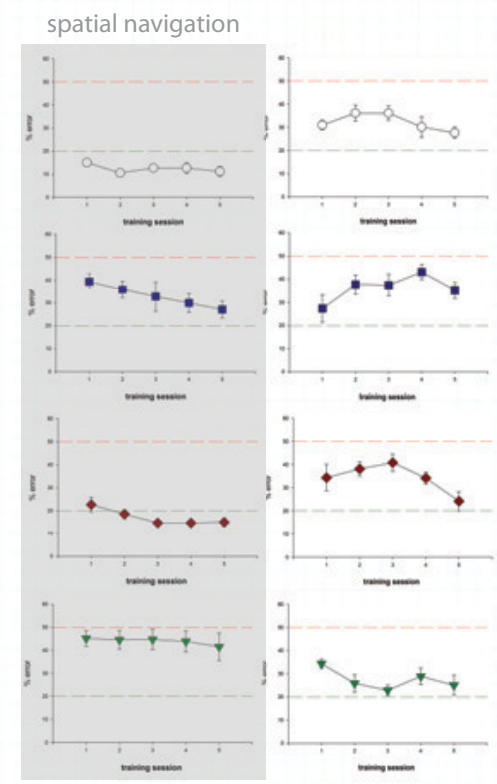

Figure 5. Acquisition of a new task after retention testing. $A$, After extensive experience with cue response, normal animals performed well in the spatial navigation task during the first day of learning. In contrast, experience with spatial navigation did not facilitate acquisition of the cue-response task. Data are presented as in Figure $4 ; n=6$ rats per group. $\boldsymbol{B}$, Same data as in $\boldsymbol{A}$ above and Figure $4 A$ reorganized to emphasize the effect of previous experience (gray highlight) on acquisition of the new task.

performed significantly better than the other groups. This finding echoes similar effects previously reported on improved performance of S-R tasks after disruption of HPC activity (Packard and White, 1989; McDonald and White, 1993). Together, the results of the acquisition tests revealed a specific facilitating effect of response learning on spatial navigation that appears to be independent of DSM. In contrast, experience with spatial navigation either does not help response learning or it may even delay it, and, if so, the effect may be dependent on the HPC function. To distinguish between a neutral versus a detrimental effect, we needed to know how fast normal rats acquired the cue-response task during the training phase.

\section{Explicit acquisition of place learning delayed} cue-response learning

Assessment of learning during the training phase, before the surgery, included data from all animals that participated in this study (spatial navigation, $n=50$; cue response, $n=55$; concurrent, $n=$ 57). At this stage, each animal was trained until achieving a performance criterion of maximum $20 \%$ error during 2 consecutive days. Because this procedure entailed a variable number of training session across the three groups of animals, we computed the frequency distribution of the number of days each animal needed to reach criterion (Fig. 6). Achieving criterion level in the concurrent condition required good performance in both tasks during the same day, which can occur at a different point in time than 


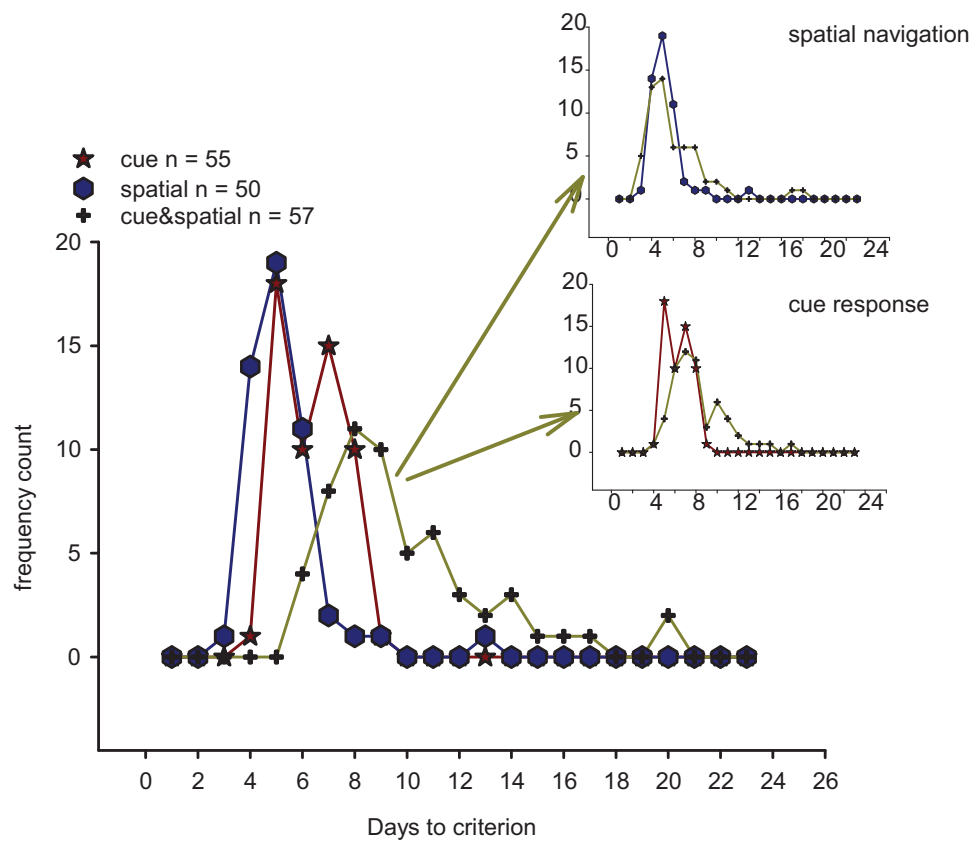

Figure 6. Acquisition during the initial training period. When trained in only one task, $5 \mathrm{~d}$ of training were sufficient for most animals in the spatial task (blue, $n=50$ ) and one-third of the animals in the cue-response task (red, $n=55$ ) to attain criterion. When trained in both tasks (dark yellow, $n=57$ ), reaching criterion required more training, but isolating the number of days to reach criterion for each task and comparing with the corresponding number of days to criterion in the sequential training condition revealed that training regimen did not affect spatial learning (top right inset). In contrast, rats were delayed in reaching criterion on cue-response behavior when concurrently learning spatial navigation (bottom right inset).

when the rat reaches criterion in an individual task. Therefore, for the concurrent condition, we also counted the number of days to reach $20 \%$ error or less for 2 consecutive days in each task regardless of performance in the other task. The resulting frequency distributions (referred to below as "cue," "spatial," "double-cue," and "double-spatial" in correspondence to the training regimen that originated them) were compared using Kolmogorov-Smirnov tests.

The cue frequency distribution was bimodal, indicating that some rats were "fast" and some rats were "slow" response learners. After $5 \mathrm{~d}$ of training, 33\% (19 of 55) of the animals trained in the cue condition performed at criterion (the fast learners; see more on this point below). In contrast, no animals (zero of six) reached criterion in the same task if trained after spatial navigation (acquisition data, above). Therefore, it seems that previous experience with spatial learning indeed delays response learning. This result led to a second question: does concurrent spatial learning have a similar effect on response learning? The data suggested that this is also the case. Rats in the double-cue condition needed more time to reach criterion than animals in the cue condition, and, after $5 \mathrm{~d}$ of training, only $9 \%$ (5 of 57) of the rats in the double-cue condition performed at $20 \%$ or less error rate (Fig. 5, bottom inset; $D=0.32, p=0.0052$ ). The cue and doublecue distributions were both bimodal, but the two curves were phased off by $2 \mathrm{~d}$ for the first peak and $3 \mathrm{~d}$ for the second peak. Furthermore, if concurrent spatial learning affects response learning, is the reverse true, i.e., does concurrent cue learning have an effect on spatial learning? The data did not support this hypothesis: the spatial and double-spatial distributions were similar (Fig. 5, top inset; $D=0.233, p=0.11$ ). Moreover, these curves were unimodal, indicating that there are no slow and fast spatial learners. How then does the rate of spatial learning compare with the fast and slow rate in the response task? The cue and spatial distributions (Fig. 6, main) were, unsurprisingly, widely dissimilar $(D=$ $0.3727, p=0.0015)$ although both medians occurred at the $5 \mathrm{~d}$ time point, which corresponds to the fast response category. At this time mark, 38\% (19 of 50) of the rats in the spatial group and 33\% (19 of 55 ) of the rats in the cue group had acquired the task. However, on average, response learning developed slower than place learning (mean $\pm \mathrm{SD}, 6.33 \pm 1.21 \mathrm{vs}$ $5.28 \pm 1.58 \mathrm{~d}$, respectively). Thus, the results of this analysis suggest that exposure to spatial learning, previous or concurrent, delays cue-response learning, whereas the converse is not true; cueresponse learning occurs slow or fast; and fast cue-response learning rate is similar to spatial learning rate.

\section{Discussion}

The present study used similar procedures as the ones previously used to generate the large body of data leading to the memory systems theory (e.g., neurotoxic lesions). Thus, the results not only thoroughly integrate within that literature but also are based on complete and permanent disruption of neural function in large brain areas, such as the HPC and DS, a condition desirable for evaluating both the contribution of such structures to memory-guided behavior (Südhof, 2015) and the function of the spared circuitry, with its compensatory abilities. During any given experience, multiple memory traces are formed and stored through the parallel activity of the memory systems; depending on circumstances, one of these traces will be selected to control behavioral output (White et al., 2013). However, the process of selection, crucial for the memory circuits to accomplish their function, remains poorly understood. Hippocampal and striatal memory systems can interact either competitively or synergistically to direct behavior (Packard et al., 1989; McDonald and White, 1995; Poldrack et al., 2001; Poldrack and Packard, 2003; Foerde et al., 2013; White et al., 2013; Wimmer et al., 2014). Multiple factors are involved in these interactions (White, 2004; Packard and Goodman, 2013), and the current state of the field is in some aspects similar to the state of hippocampal research in the early 1970s, before the publication of O'Keefe and Nadel's theory of hippocampus as a cognitive map (O'Keefe and Nadel, 1978): we have many pieces of the puzzle, but we do not yet know how they fit together. A recently formulated new model of interaction between memory systems may turn out to provide the organizing theoretical framework. Starting from a putative two-process model for hippocampal contribution to context conditioning (Rudy et al., 2004) and based on empirical results suggesting information transfer between memory systems (Corbit and Balleine, 2005; Corbit and Janak, 2007), White and collaborators elaborated on their previous work to propose an expanded parallel processing model in which the hippocampus, striatum, and amygdala memory systems, although still acting independently and in parallel, can also interact indirectly, through the common cortical representation all systems create (White, 2004; White et al., 2013; Fig. 7A). The current data lend support to this theory. When 


\section{A}
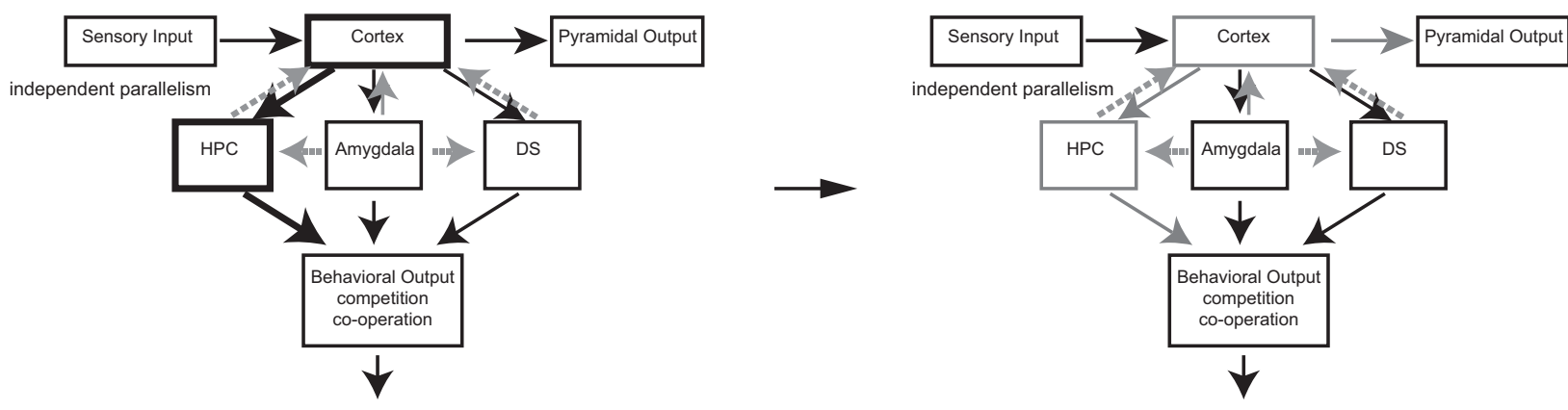

\section{B}

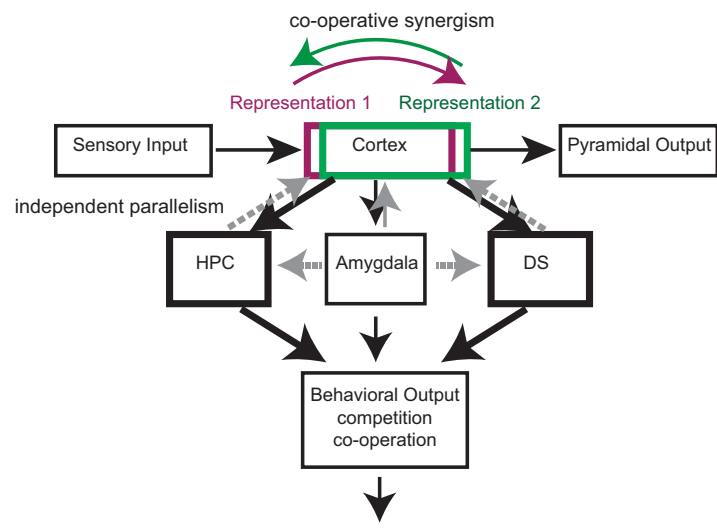

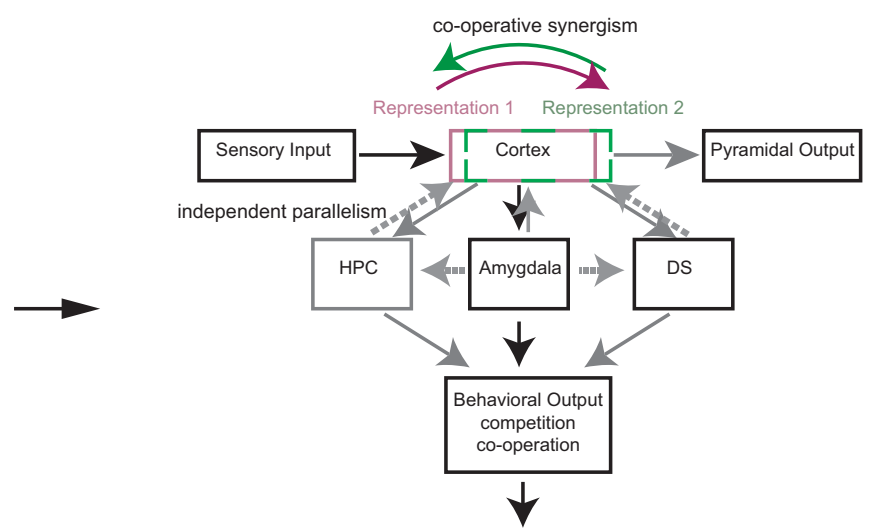

Figure 7. Expanded parallel processing model. $\boldsymbol{A}$, Left, The three memory systems (HPC, amygdala, and DS) receive information from the cortex, process it in parallel to form memory traces (thick lines indicate the HPC memory trace), and use it to guide behavior (black arrows). The amygdala also modulates the HPC and DS memory systems (gray horizontal arrows). Output from all memory systems is sent back to the cortex to be incorporated in the complex representation of a given experience (dashed arrows). Through the cortex, memory systems can indirectly influence each other. Right, HPC damage degrades but does not obliterate the cortical representation, and the other intact memory traces can continue to exert their influence over behavior. $\boldsymbol{B}$, Left, Two very similar but not identical experiences, in which the HPC and DS memory systems guide behavior, respectively, result in two cortical representations that share much of their neural basis. The two similar cortical representations constitute the basis of cooperative synergism: activity of the HPC memory system may get co-opted in the performance of a behavior supported by an HPC-independent S-R association. The converse is also true for the DS memory system. Right, HPC damage results in degradation of both cortical representations. This process can in turn temporarily affect behavioral performance based on $S-R$ associations. Subsequent training leads to the formation of a new cortical representation and reduction of the behavioral deficit. Adapted from White (2004).

animals learn one task at a time, the formation of the cortical representation is led, perhaps primarily or perhaps initially, by input from the memory system whose style of processing is most suitable to the problem the animal faces (White and McDonald, 2002). The representation also encompasses the processing output of other memory systems, which are active in parallel. In such circumstances, independent parallelism is predominant as a functional principle. Damage of the "leading" memory system degrades but does not obliterate the cortical representation, and results in behavioral deficits as long as the problem that the organism faces is the "domain" of the damaged memory system; otherwise, behavior may be unaffected. This hypothesis would explain why someone like H.M. may not explicitly remember an event but would nonetheless be able to emotionally react to it. The integrated cortical representation would also provide the means whereby information acquired in circumstances most relevant to the processing style of one memory system can be subsequently used in situations most relevant to the processing style of a different memory system. For example, explicitly learning an S-R association, which involves the DS, can be later used to guide behavior based on a stimulus-reinforcement association, known to require the activity of the amygdala memory system (McDonald and Hong, 2004; McDonald et al., 2004).

When animals learn two tasks concurrently in the same environment, two very similar yet distinct representations are formed (Fig. 7B). The memory systems may operate based on cooperative synergism because the two similar (although not identical) cortical representations can cause a memory system to support incongruent behavior (i.e., behavior based on a representation incongruent with the type of memory trace that the particular memory system forms). Damage of the memory system can then impair behavior typically supported by a different memory system. Second, the model can also explain how protracted interaction between striatal and hippocampal memory systems may occur when learning experiences take place in the same environment. The representation formed when the animal learns the first task may be reactivated by the environment and can influence subsequent novel learning even as the brain forms a second, different representation.

DSL, also known as the sensorimotor striatum because of its connections with the sensorimotor cortices, has been primarily linked to memory for S-R associations and habits, a model-free type of behavior based on automatism. In contrast, DSM has been associated with model-based behavior, which is responsive to outcome and involves behavioral flexibility (Devan et al., 1999; Yin and Knowlton, 2004, 2006; Yin et al., 2005; Ragozzino et al., 2009; Devan et al., 2011). Several physiological recording experiments also linked DSM activity and choice (DeCoteau et al., 2007; Thorn et al., 2010; Delcasso et al., 2014; Regier et al., 2015). The current results support this view. DSM was involved in both 
spatial navigation and cue response regardless of training experience, a finding compatible with a role for DSM in supporting appropriate changes of body turns in pursuit of the goal. However, systematic stereotyped behavior (i.e., perseverance of a specific body turn) caused poor performance only in a relatively restricted subset of the animals with DSM lesions; in some cases, the rats relinquished the body turn strategy with training. Furthermore, DSM function did not seem to be required for normal animals to switch from cue response to spatial navigation. Thus, DSM seems to be indeed working along other neural circuits to flexibly associate body movements with a changing goal, rather than direct the choice of behavioral strategy.

According to the current view, habits interfere with, and eventually supersede, behaviors based on cognitive type of memory. This was shown for example in the seminal work of Packard and McGaugh (1996): the initially prevalent hippocampal-dependent spatial strategy was abandoned in favor of a striatum-dependent response strategy, suggesting that habits take time to form, but once acquired, they dominate behavior. In contrast, our data suggest that habits may actively contribute to model-based behavior, at least in certain conditions. These results corroborate similar previous findings that in normal animals, experience with a response strategy facilitates spatial learning while the converse is not true (Ragozzino et al., 1999). Furthermore, rats with DSM lesions extensively trained in the cue-response task were also able to immediately adapt when they were exposed to a spatial task, whereas lesions of the habitsupporting DSL interfered with this ability. This finding suggests that it is indeed the intrinsically asymmetric character of interaction between the striatum and hippocampal memory systems that is reflected in the asymmetry of results obtained with sequential training, rather than a behavioral modulation exerted by DSM. In addition, because experience with a cognitive strategy consistently impeded S-R learning regardless of whether the learning took place sequentially or concurrently, one intriguing possibility is that interference from the hippocampal memory system may be part of the explanation behind the slowness of habit formation processes. The bimodal nature of the cue and double-cue distributions (which corroborates previously reported dichotomy between place learners and cue learners in the normal population; McDonald and White, 1994) and the shift of the fast response learning to slow rate after experience with the spatial task are in line with this hypothesis. If true, one may speculate on the interaction between cognitive memory and drug addiction. It is well documented in the clinical literature that exposure to a context previously associated with intake of an addictive substance can trigger relapse. Despite its importance, the mechanism whereby the hippocampal-dependent context memory prompts a compulsive striatum-dependent behavior remains unclear. One possibility is that normally, the hippocampal memory system "slows down" the striatal memory system, thus preventing an automatic response to take precedence regardless of circumstances. Part of the neural processes involved in addiction may lead to a change in the direction of this interaction, so that the hippocampal memory system facilitates the control of striatal memory system over behavior. The postulated interaction through cortical representations formulated in the model above certainly allows for this possibility. At this point, this possibility remains a mere speculation. Additional systematic research is currently needed to understand more fully the interaction between memory systems.

\section{Notes}

Supplemental material for this article is available at http://biorxiv.org/ content/early/2016/02/26/041459.figures-only. Tabulated information of lesions and results of statistical analysis. This material has not been peer reviewed.

\section{References}

Baker PM, Ragozzino ME (2014) Contralateral disconnection of the rat prelimbic cortex and dorsomedial striatum impairs cue-guided behavioral switching. Learn Mem 21:368-379. CrossRef Medline

Chang Q, Gold PE (2003) Intra-hippocampal lidocaine injections impair acquisition of a place task and facilitate acquisition of a response task in rats. Behav Brain Res 144:19-24. CrossRef Medline

Corbit LH, Balleine BW (2005) Double dissociation of basolateral and central amygdala lesions on the general and outcome-specific forms of pavlovian-instrumental transfer. J Neurosci 25:962-970. CrossRef Medline

Corbit LH, Janak PH (2007) Inactivation of the lateral but not medial dorsal striatum eliminates the excitatory impact of pavlovian stimuli on instrumental responding. J Neurosci 27:13977-13981. CrossRef Medline

Corkin S (1968) Acquisition of motor skill after bilateral medial temporallobe excision. Neuropsychologia 6:255-265. CrossRef

DeCoteau WE, Thorn C, Gibson DJ, Courtemanche R, Mitra P, Kubota Y, Graybiel AM (2007) Learning-related coordination of striatal and hippocampal theta rhythms during acquisition of a procedural maze task. Proc Natl Acad Sci U S A 104:5644-5649. CrossRef Medline

Delcasso S, Huh N, Byeon JS, Lee J, Jung MW, Lee I (2014) Functional relationships between the hippocampus and dorsomedial striatum in learning a visual scene-based memory task in rats. J Neurosci 34:1553415547. CrossRef Medline

Devan BD, White NM (1999) Parallel information processing in the dorsal striatum: relation to hippocampal function. J Neurosci 19:2789-2798. Medline

Devan BD, McDonald RJ, White NM (1999) Effects of medial and lateral caudate-putamen lesions on place- and cue-guided behaviors in the water maze: relation to thigmotaxis. Behav Brain Res 100:5-14. Medline

Devan BD, Hong NS, McDonald RJ (2011) Parallel associative processing in the dorsal striatum: segregation of stimulus-response and cognitive control subregions. Neurobiol Learn Mem 96:95-120. CrossRef Medline

Ferbinteanu J, Shapiro ML (2003) Prospective and retrospective memory coding in the hippocampus. Neuron 40:1227-1239. CrossRef Medline

Ferbinteanu J, Shirvalkar P, Shapiro ML (2011) Memory modulates journey-dependent coding in the rat hippocampus. J Neurosci 31:91359146. CrossRef Medline

Foerde K, Race E, Verfaellie M, Shohamy D (2013) A role for the medial temporal lobe in feedback-driven learning: evidence from amnesia. J Neurosci 33:5698-5704. CrossRef Medline

Heindel WC, Butters N, Salmon DP (1988) Impaired learning of a motor skill in patients with Huntington's disease. Behav Neurosci 102:141-147. CrossRef Medline

Hull C (1930) Knowledge and purpose as habit mechanisms. Psychol Rev 37:511. CrossRef

Knowlton BJ, Mangels JA, Squire LR (1996) A neostriatal habit learning system in humans. Science 273:1399-1402. CrossRef Medline

McDonald RJ, Hong NS (2004) A dissociation of dorso-lateral striatum and amygdala function on the same stimulus-response habit task. Neuroscience 124:507-513. CrossRef Medline

McDonald RJ, White NM (1993) A triple dissociation of memory systems: hippocampus, amygdala, and dorsal striatum. Behav Neurosci 107:3-22. CrossRef Medline

McDonald RJ, White NM (1994) Parallel information processing in the water maze: evidence for independent memory systems involving dorsal striatum and hippocampus. Behav Neural Biol 61:260-270. CrossRef Medline

McDonald RJ, White NM (1995) Hippocampal and nonhippocampal contributions to place learning in rats. Behav Neurosci 109:579-591. CrossRef Medline

McDonald RJ, Foong N, Hong NS (2004) Incidental information acquired by the amygdala during acquisition of a stimulus-response habit task. Exp Brain Res 159:72-83. Medline

McGeorge AJ, Faull RL (1989) The organization of the projection from the cerebral cortex to the striatum in the rat. Neuroscience 29:503-537. CrossRef Medline

Milner B, Corkin S, Teuber HL (1968) Further analysis of the hippocampal amnesic syndrome: 14-year follow-up study of HM. Neuropsychologia 6:215-234. CrossRef 
O’Keefe J, Nadel L (1978) The hippocampus as a cognitive map. Oxford, UK: Oxford UP.

O’Reilly KC, Alarcon JM, Ferbinteanu J (2014) Relative contributions of $\mathrm{CA} 3$ and medial entorhinal cortex to memory in rats. Front Behav Neurosci 8:292. CrossRef Medline

Packard MG, McGaugh JL (1996) Inactivation of hippocampus or caudate nucleus with lidocaine differentially affects expression of place and response learning. Neurobiol Learn Mem 65:65-72.

Packard MG, Goodman J (2013) Factors that influence the relative use of multiple memory systems. Hippocampus 23:1044-1052. CrossRef Medline

Packard MG, White NM (1989) Memory facilitation produced by dopamine agonists: role of receptor subtype and mnemonic requirements. Pharmacol Biochem Behav 33:511-518. CrossRef Medline

Packard MG, Hirsh R, White NM (1989) Differential effects of fornix and caudate nucleus lesions on two radial maze tasks: evidence for multiple memory systems. J Neurosci 9:1465-1472. Medline

Paxinos G, Watson C (1988) The rat brain in stereotaxic coordinates, Ed 4. San Diego: Academic.

Penfield W, Milner B (1958) Memory deficit produced by bilateral lesions in the hippocampal zone. AMA Arch Neurol Psychiatry 79:475-497. CrossRef Medline

Poldrack RA, Packard MG (2003) Competition among multiple memory systems: converging evidence from animal and human brain studies. Neuropsychologia 41:245-251. CrossRef Medline

Poldrack RA, Clark J, Paré-Blagoev EJ, Shohamy D, Creso Moyano J, Myers C, Gluck MA (2001) Interactive memory systems in the human brain. Nature 414:546-550. CrossRef Medline

Ragozzino ME (2007) The contribution of the medial prefrontal cortex, orbitofrontal cortex, and dorsomedial striatum to behavioral flexibility. Ann N Y Acad Sci 1121:355-375. CrossRef Medline

Ragozzino ME, Detrick S, Kesner RP (1999) Involvement of the prelimbicinfralimbic areas of the rodent prefrontal cortex in behavioral flexibility for place and response learning. J Neurosci 19:4585-4594. Medline

Ragozzino ME, Mohler EG, Prior M, Palencia CA, Rozman S (2009) Acetylcholine activity in selective striatal regions supports behavioral flexibility. Neurobiol Learn Mem 91:13-22. CrossRef Medline

Regier PS, Amemiya S, Redish AD (2015) Hippocampus and subregions of the dorsal striatum respond differently to a behavioral strategy change on a spatial navigation task. J Neurophysiol 114:1399-1416. CrossRef Medline

Rudy JW, Huff NC, Matus-Amat P (2004) Understanding contextual fear conditioning: insights from a two-process model. Neurosci Biobehav Rev 28:675-685. CrossRef Medline

Scoville WB, Milner B (1957) Loss of recent memory after bilateral hippocampal lesions. J Neurol Neurosurg Psychiatry 20:11-21. CrossRef Medline

Squire LR (2004) Memory systems of the brain: a brief history and current perspective. Neurobiol Learn Mem 82:171-177. CrossRef Medline

Südhof TC (2015) Reproducibility: experimental mismatch in neural circuits. Nature 528:338-339. CrossRef Medline

Thorndike EL (1932) The fundamentals of learning. Teachers College Bureau of Publication. New York, NY: Columbia University.

Thorn CA, Atallah H, Howe M, Graybiel AM (2010) Differential dynamics of activity changes in dorsolateral and dorsomedial striatal loops during learning. Neuron 66:781-795. CrossRef Medline

Tolman EC (1948) Cognitive maps in rats and men. Psychol Rev 55: 189-208. CrossRef Medline

Tolman EC, Ritchie BF, Kalish D (1946) Studies in spatial learning. II. Place learning versus response learning. J Exp Psychol 36:221-229. Medline

White NM (2004) The role of stimulus ambiguity and movement in spatial navigation: a multiple memory systems analysis of location discrimination. Neurobiol Learn Mem 82:216-229. CrossRef Medline

White NM, McDonald RJ (2002) Multiple parallel memory systems in the brain of the rat. Neurobiol Learn Mem 77:125-184. CrossRef Medline

White NM, Packard MG, McDonald RJ (2013) Dissociation of memory systems: the story unfolds. Behav Neurosci 127:813-834. CrossRef Medline

Wimmer GE, Braun EK, Daw ND, Shohamy D (2014) Episodic memory encoding interferes with reward learning and decreases striatal prediction errors. J Neurosci 34:14901-14912. CrossRef Medline

Yin HH, Knowlton BJ (2004) Contributions of striatal subregions to place and response learning. Learn Mem 11:459-463. CrossRef Medline

Yin HH, Knowlton BJ (2006) The role of the basal ganglia in habit formation. Nat Rev Neurosci 7:464-476. CrossRef Medline

Yin HH, Ostlund SB, Knowlton BJ, Balleine BW (2005) The role of the dorsomedial striatum in instrumental conditioning. Eur J Neurosci 22: 513-523. CrossRef Medline 